\title{
Luz e sombra na história da historiografia
}

Light and shadow in the history of historiography

PALLARES-BURKE, Maria Lúcia Garcia. O triunfo do fracasso: Rüdiger Bilden, o amigo esquecido de Gilberto Freyre. São Paulo: Editora Unesp, 2012. 423p.

\section{Rafael Petry Trapp}

rafaelpetrytrapp@gmail.com

Doutorando em História

Universidade Federal Fluminense

Rua Ramiro Barcelos, 1069 - Centro

96810-054 - Santa Cruz do Sul - Rio Grande do Sul

Brasil

Palavras-chave

Historiografia; Biografia; História intelectual.

Keywords

Historiography; Biography; Intellectual history.

194 
Que interesse pode haver no estudo de trajetórias de intelectuais esquecidos? O que significa e como definir o "fracasso" na história das ideias? Como os campos historiográficos, no Brasil e alhures, se constituem e se legitimam também a partir de exclusões? Tendo por base essas e outras perguntas, o livro da historiadora Maria Lúcia Pallares-Burke, O triunfo do fracasso, traz à tona a trajetória pessoal e intelectual de Rüdiger Bilden. Alemão, nascido em Eschweiller em 1893, tendo imigrado para os Estados Unidos e se radicado em Nova York em 1914, Bilden foi uma figura ímpar no campo de estudos de história da escravidão e das relações raciais no Brasil entre as décadas de 1920-40. Seu nome e pensamento, entretanto, por terem se perdido nas malhas do tempo, constituíam tênues linhas de uma obscurecida nota de rodapé na história da historiografia. O trabalho de Pallares-Burke remodela esse quadro.

Quando falamos que Bilden, na história da historiografia, figurava como uma esmaecida "nota de rodapé", nos referimos ao fato de ele ser lembrado quando, e nas poucas vezes, que o foi - por sua estreita relação com Gilberto Freyre, cultivada ao longo de várias décadas, a partir do início dos anos 1920, quando se conheceram e se tornaram amigos na Columbia University. Um dos aspectos concretos dessa relação está consubstanciado nada menos que em Casa-Grande \& Senzala (1933). Ao tomar em mãos a obra, Bilden ficou estupefato por nela encontrar algumas das teses sobre a história brasileira que ele desenvolvia - e que compartilhava com Freyre - ao longo dos anos 1920, tendo em vista um livro que, por infortúnios diversos, não chegou a ser concluído. Tal fato de imediato nos intriga e prende a atenção, e talvez aí encontremos razão para o subtítulo "Rüdiger Bilden, o amigo esquecido de Gilberto Freyre", chamariz que, felizmente, não condiz com a obra como um todo.

O livro é fruto do que a autora denomina de uma "obsessão" sobre o mistério em torno do nome de Rüdiger Bilden - até então aparentemente coadjuvante -, que pululava nos documentos de suas pesquisas sobre o jovem Gilberto Freyre - trabalho que redundou, aliás, em uma aclamada biografia intelectual do período de formação do sociólogo pernambucano (Cf. PALLARES-BURKE 2005). O livro é escrito a partir das parcas fontes documentais disponíveis, a maioria delas constituída de correspondências e textos esparsos do historiador alemão, encontrados em arquivos na Alemanha, Estados Unidos e Brasil. A partir de uma minuciosa, exaustiva e criativa pesquisa, portanto, a historiadora reconstitui a singular e dramática biografia do personagem em questão.

A reflexão inicial parte de uma discussão sobre os "vencedores" e os "perdedores" na história. Por que estudar a trajetória de um loser como Bilden? Um intelectual que nunca finalizou um livro, nem teve uma posição de destaque no mundo acadêmico, um sujeito esquecido, legado ao ostracismo? Revisando olhares e mudanças pelas quais passou o campo historiográfico mais geral no século XX sobre quais indivíduos, ou tipos de indivíduos, merecem ser alvo da atenção historiadora, a constatação - plena de uma obviedade ofuscada - recai no fato de que qualquer vida humana é interessante, de que a condição humana está presente, de formas diversas, em qualquer sujeito. Os "perdedores" também imprimem sua marca nos processos históricos que vivenciaram, ainda 
que nem sempre com lances gloriosos. Nos meandros da história intelectual, por debaixo de histórias silenciadas, de projetos inacabados, de livros inconclusos ou abandonados, o estudo dessas trajetórias fenecidas pode desvelar sentidos inauditos do que se poderia tomar por "vitória", como se mostra o caso de Bilden. O "triunfo do fracasso", na definição de Pallares-Burke.

O núcleo central do livro é dividido em cinco capítulos. Os três primeiros recobrem a trajetória de Rüdiger Bilden desde a vida na Alemanha, a mudança para Nova York em meados dos anos 1910, a decisiva passagem pela Columbia na década de 1920, a viagem ao Brasil e as desventuras várias que fizeram com que seu inovador livro - que consistiria, na realidade, no texto de uma tese de doutorado - sobre o papel da escravidão na história brasileira não viesse a lume.

O interesse de Bilden na história do Brasil constituiu-se no decorrer de sua formação na Columbia, iniciada a partir de 1917. Nessa instituição o jovem estudante alemão pôde se relacionar com intelectuais como o antropólogo Franz Boas e o historiador William Shepherd. Este último, um dos primeiros historiadores norte-americanos a se interessar pela América Latina, foi pessoa decisiva para que Bilden se debruçasse já na pós-graduação, em 1922, sobre o tema, ainda insuficientemente inexplorado, da influência da escravidão no desenvolvimento histórico do Brasil.

A área de estudos de história latino-americana e brasileira estava tomando corpo nesse período na Columbia, através do empenho de Shepherd, que se tornou importante mentor intelectual do estudante alemão. Tendo recebido

196 duas bolsas de estudo entre 1922 e 1924, que the franquearam estabilidade financeira, Bilden se dedicou com afinco ao tema de seu doutorado em curso, que tinha por título Slavery as a Factor in Brazilian History. A boa situação de vida, que se mostraria depois, desafortunadamente, episódica, permitiu-lhe também uma viagem de estudos ao Brasil, que se concretizou, com a ajuda do amigo diplomata e historiador Oliveira Lima, em 1925.

A viagem de pesquisa para o Brasil marcou profundamente o jovem Bilden, que definia com mais precisão os contornos da nova abordagem histórica que trazia - ou, melhor dizendo, que praticamente inventava. Viajando por Pernambuco, Bahia, Rio de Janeiro, Minas Gerais e São Paulo, tomava corpo em seu espírito a ideia do Brasil como um "laboratório de civilização". Já nos Estados Unidos, em 1927, retornando do Brasil - país que ele jamais tornaria a ver novamente -, esperava-se que o conjunto de suas ideias, fontes e impressões de viagem tomasse corpo no livro que ensaiava.

Um sinal de como este trabalho vinha tomando forma está no artigo que ele publicou na revista norte-americana The Nation, em 1929, intitulado "Brazil, Laboratory of Civilization". Neste texto o autor afirmava, contrapondo-se frontalmente às ideias ainda em voga do racismo científico, que a alegada inferioridade do Brasil tinha razões históricas e culturais, nada tendo de biológico ou racial. Considerava o sistema colonial brasileiro assentado sobre três aspectos, quais sejam a monocultura latifundiária, a escravidão e a miscigenação, os quais teriam ensejado a produção histórica de um novo e alternativo modelo de civilização. Sem negar os antagonismos raciais e resíduos de discriminação, Bilden 
asseverava que esses antagonismos se davam mais em termos de categorias sociais, tais como "senhores" e "escravos", do que entre raças - brancos, negros, índios e mestiços. Em suas palavras, "a causa dos males não é a raça: foi a escravidão" (BILDEN apud PALLARES-BURKE 2012, p. 193).

O artigo no The Nation terminou por ser a única amostra publicada do que teria sido o "livro que não foi". Não são muito claras as razões concretas pelas quais o trabalho doutoral de Bilden não chegou a termo, mas a autora apresenta hipóteses plausíveis. Entre elas estariam, certamente, a imensa amplitude - e ambição - do projeto de pesquisa, fato admitido por ele mesmo; alguns trabalhos que assumiu nos anos seguintes, como de professor na Fisk University, no Tennessee, que Ihe tomavam, pela dedicação que despendia com seus alunos, bastante tempo; certo "esvaziamento", com a aparição de Casa-Grande \& Senzala, em 1933, do tema que ele se propunha a investigar; e também os problemas pessoais - como intermitentes depressões - e as imensas dificuldades financeiras que o acompanhariam, infelizmente, pela maior parte de sua vida. Pallares-Burke, aliás, é pródiga em demonstrar como a condição de estrangeiro foi muitas vezes decisiva para os infortúnios de Bilden. Vivendo em uma época agitada pelas duas grandes guerras mundiais, o fato de ser alemão nos Estados Unidos mostrou-se um peso às vezes difícil de ser superado.

"Para além do livro que não foi" constitui o título dos dois últimos capítulos do livro, que abordam o período de sua trajetória da década de 1930 até 1956. Bilden votou-se, em meados dos anos 1930, à docência em algumas instituições de ensino e também ao ativismo junto ao efervescente movimento negro. Em 1936 conseguiu uma oportunidade de se dedicar à sua especialidade na Fisk University, notória universidade negra. Sua experiência como professor universitário, todavia, durou apenas até o término do contrato, em 1938. A partir daí ministrou cursos esporádicos sobre relações raciais em instituições como o Harlem Labor Center, em Nova York, e o Tuskegee Institute, do Alabama. Foi também nesse período que conheceu e se tornou próximo de vários membros da intelligentsia negra da "Renascença do Harlem", como Arthur Schomburg e Aaron Douglas. Bilden era reconhecido como autoridade no campo de história da escravidão e das relações raciais no Brasil, e mostrou-se sempre interessado, comprometido e atuante com as questões do negro e do racismo nos Estados Unidos.

A partir do final dos anos 1950, com o livro sobre o Brasil deixado de lado, projetos fracassados e muita dificuldade em conseguir uma posição como professor nos Estados Unidos, Bilden tornou-se o obscuro espectro de que falávamos no início do texto. Teria terminado seus dias como escriturário, vivendo em um melancólico apartamento em algum lugar ignorado de Greenwich Village, Manhattan. Morreu, ao que tudo indica, esquecido e abandonado, em 1980.

Finalmente, no "Epílogo" Pallares-Burke aborda a relação entre o historiador alemão e Gilberto Freyre. Na Columbia, nos anos 1920, os dois fizeram de uma sólida amizade também esteio de relações e trocas intelectuais. O jovem Freyre deixara patente a admiração por Bilden em um elogioso artigo escrito sobre o trabalho do amigo para o Diário de Pernambuco, em 17 de janeiro de 1926. O teor da avaliação positiva do trabalho de Bilden, contudo, mudou 
sensivelmente quando esse mesmo artigo foi republicado décadas mais tarde, em 1979, no livro Tempo de Aprendiz. A autora demonstra como Freyre faz um imenso esforço em mudar o sentido de suas afirmações pretéritas, em um claro exercício derrogatório do papel que Bilden teve em sua trajetória e para suas perspectivas intelectuais, especialmente aquelas de Casa-Grande \& Senzala. O exemplo descrito é sintomático, entre outros apresentados no livro, da obtusa postura ulterior do sociólogo brasileiro frente a alguém que ele sabia ser muito importante - e que passou a ser visto como uma presença incômoda em sua biografia intelectual. Mostra-se acertada, portanto, a escolha da autora em tratar da relação entre Bilden e Freyre em epílogo, não submetendo um à enfezada sombra do outro.

O livro de Pallares-Burke inaugura a historiografia sobre a trajetória e pensamento de Bilden, e redimensiona, em vários aspectos, o quadro mais geral das interpretações históricas e historiográficas, no Brasil e nos Estados Unidos, sobre as temáticas da escravidão, miscigenação e relações raciais brasileiras. Se não se pode, em absoluto, negar a genialidade de Freyre em desenvolver as ideias centrais de Casa-Grande \& Senzala, estas não podem mais ser vistas sem se passar por uma revisão crítica que aponte as relações entre o pensamento deste para com o de Bilden, reflexão que o paciente e obstinado trabalho de Pallares-Burke traz à tona.

Embora se trate de um livro de cunho biográfico, é importante frisar também que a autora preserva um lúcido olhar analítico para as questões de ordem mais contextual. Além de todas as articulações que são estabelecidas entre a trajetória de Bilden com as problemáticas mais amplas de seu tempo, como as guerras mundiais, o racismo e os movimentos pelos direitos civis nos Estados Unidos, a leitura nos possibilita uma melhor compreensão da formação dos estudos brasileiros neste país, bem como da própria historiografia brasileira, ainda que marcada, nesse caso, por uma exclusão.

Para além das dificuldades que a vida reservou a Bilden, e contra as quais ele não pôde a contento se desvencilhar, a figura do historiador alemão emerge no belíssimo texto de Pallares-Burke não mais como uma "nota de rodapé", mas sim como personagem de um capítulo fundamental e estruturante da historiografia brasileira. O triunfo do fracasso é um soberbo trabalho de pesquisa, que desvela o que há de mais "humano, demasiado humano" na formação dos campos intelectuais e historiográficos mundo afora. É, sobretudo, um testemunho sensível sobre a vida de Rüdiger Bilden, um indivíduo profundamente imerso nas questões, problemas e dilemas de seu tempo, e que ganha, com a presente obra, um verdadeiro e merecido reconhecimento. 